\title{
Fire Whirl due to Interaction between Line Fire and Cross Wind
}

\author{
KUIBIN ZHOU ${ }^{a, b}$, NAIAN LIU ${ }^{a}$, PANPAN YIN ${ }^{a}$, XIESHANG YUAN ${ }^{a}$, JUNCHENG JIANG $^{b}$ \\ ${ }^{a}$ State Key Lab of Fire Science, University of Science and Technology of China \\ Hefei, Anhui 230026, China \\ ${ }^{\mathrm{b}}$ College of Urban Construction \& Safety Engineering, Nanjing University of Technology, Nanjing, \\ Jiangsu, 210009, China
}

\begin{abstract}
During the wildland fire of Brazil in 2010 (http://www.dailymail.co.uk/sciencetech/article-1306088/Braziltornado-Whirling-column-flames-sweeps-burning-fields.html), a special fire whirl occurred over a narrow but long fire front and moved due to the wind effect. This paper presents an elementary study on such a moving fire whirl by conducting line fire experiments with cross wind. Experimental analysis indicates that a line fire near the ground, a reasonable attack angle between the line fire and the cross wind, and wind speed within a critical range are the three essential conditions for the formation of fire whirl in a line fire. By examining the advection and bending of vorticity, it is also deduced that the concentrated vortex of fire whirl results from the coupling of the line fire plume and the horizontal vortex line near the ground surface. By assuming the solid-body rotation of fire whirl flame, a possible mechanism of moving fire whirl is proposed, which states that the flame moving is mainly controlled by the drag force, lift force and ground friction. Accurate experimental measurements are needed to testify or verify this mechanism in the future work.
\end{abstract}

KEYWORDS: moving fire whirl, line fire, cross wind, concentrated vortex

\section{INTRODUCTION}

Fire whirl, generally caused by unexpected concentrated vortex effect on a burning flame, is a rare but catastrophic phenomenon in natural fires. During the wildland fire of Brazil in 2010 (http://www.dailymail.co.uk/sciencetech/article-1306088/Brazil-tornado-Whirling-column-flames-sweepsburning-fields.html), a fire whirl was induced by the interaction between the long fire front and the cross wind, which was typically characterized by its flame moving behavior. Generally, the concentrated vortex of fire whirl can be generated in leeward slope [1], large fires [2] and L-shape urban fires [3, 4] under the effect of cross wind, as well as by multiple fires interaction [5]. Obviously, these atmospheric, topographic and fuel configurations are different from that of Brazil fire whirl. Recently a moving fire whirl was reconstructed by Kuwana et al [6] by scale-model experiments, in which the authors provided an elementary study on the critical wind speed for generation of moving fire whirl. However, until now the source of concentrated vortex for the moving fire whirl remains to be unexplored.

In view of the limited knowledge upon the Brazil moving fire whirl, in this paper we present an elementary investigation on the critical conditions and mechanism for the initial formation of the concentrated vortex in a line fire under wind and the subsequent behavior of flame moving. The effort consists of two parts. First, we attempt to interpret the mechanism of concentrated vortex formation based on the vortex theory, with verification by experiments. Then, regarding the fire whirl flame as a rotating solid body, we propose a possible mechanism of flame moving by some elementary physical analysis, in which the fluid forces which dominate the flame-moving behavior are identified.

\section{EXPERIMENTAL}

\section{Experimental Setup}

The simulation experiment of moving fire whirl was conducted by a system which consists of a mechanical wind wall, a sand bed, a line burner and two support frames (Fig. 1). The wind wall provided a uniform wind speed at the outlet section $(100 \mathrm{~cm}$ in width and $200 \mathrm{~cm}$ in height). The wind speed was calibrated to fit the formula $U=0.102 n-0.53$, where $n$ is the fan output frequency. On use of this formula, the output frequency should be over $0.52 \mathrm{~Hz}$. Otherwise the wind speed is regarded to be zero. The used wind system has no sidewalls, which is different from that of Kuwana et al [6]. For the detailed description of the wind 
wall system used in this work, refer to reference [7]. The centers of the sand bed and line burner were 500 $\mathrm{cm}$ away from the outlet of the wind wall. Two video cameras were used to monitor the experimental process.

Four burners of different sizes, $300 \mathrm{~cm} \times 5 \mathrm{~cm} \times 5 \mathrm{~cm}, 200 \mathrm{~cm} \times 5 \mathrm{~cm} \times 5 \mathrm{~cm}, 120 \mathrm{~cm} \times 6 \mathrm{~cm} \times 3 \mathrm{~cm}$ and $100 \mathrm{~cm} \times 3 \mathrm{~cm} \times 3 \mathrm{~cm}$, were used in experiments. The $300 \mathrm{~cm}$ and $200 \mathrm{~cm}$ long burners, respectively with the attack angles of $25^{\circ}$ and $30^{\circ}$, were used to examine the fire whirl formation and moving mechanism. In tests the burner rim was set to be $0 \mathrm{~cm}, 5 \mathrm{~cm}$ or $53 \mathrm{~cm}$ over the ground surface, in order to examine the ground surface effect. The effect of the attack angle was also studied by different burners, for which the $200 \mathrm{~cm}$ long burner involved an attack angle of $0^{\circ}$, and both the 120 and $100 \mathrm{~cm}$ long burners involved an attack angle of $90^{\circ}$. The fan output frequencies of $0,0.75,10,12.5,15,17.5$, and $20 \mathrm{~Hz}$ were adopted, with the corresponding wind speeds being $0,0.24,0.49,0.75,1.00,1.26$ and $1.51 \mathrm{~m} / \mathrm{s}$. Heptane is used as the fuel in all tests.

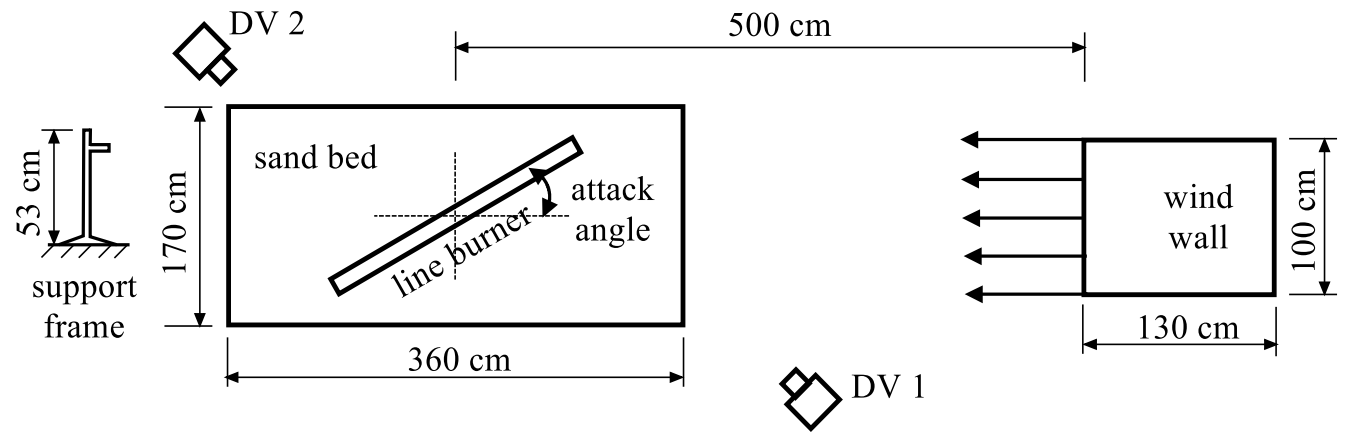

Fig. 1 Schematic for experimental setup.

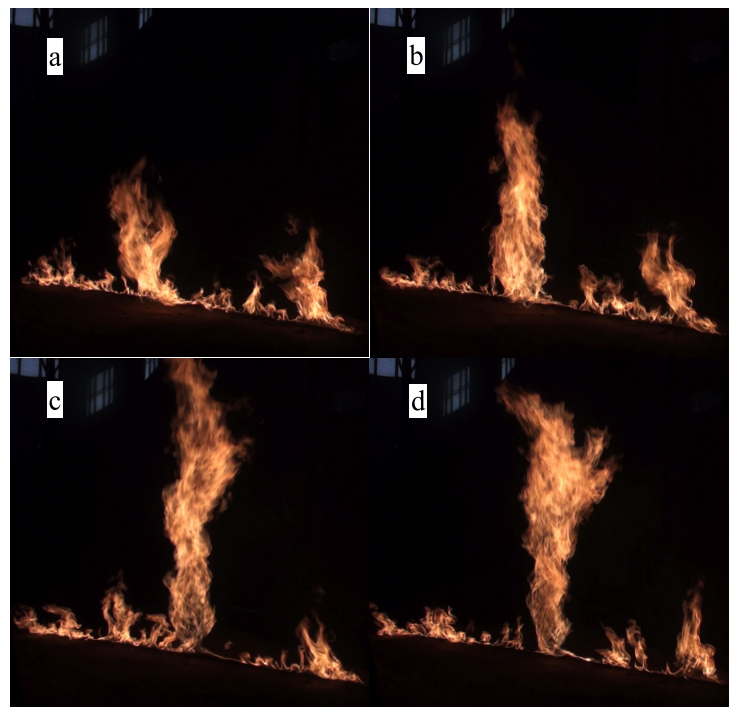

Fig. 2. Photos of the formation and downwind movement of the fire whirl obtained from DV 2, at relative time moments of (a) $0 \mathrm{~s}$, (b) $2 \mathrm{~s}$, (c) $4 \mathrm{~s}$ and (d) $6 \mathrm{~s}$. The burner was $300 \mathrm{~cm} \times 5 \mathrm{~cm} \times 5 \mathrm{~cm}$ in size, with its rim flush with the ground surface. Wind speed: $0.49 \mathrm{~m} / \mathrm{s}$; attack angle: $25^{\circ}$.

\section{Experimental Observation}

For the $300 \mathrm{~cm}$ long burner of $25^{\circ}$ attack angle with its rim being flush with the ground surface, only a weak fire whirl with a flame height below $0.6 \mathrm{~m}$ appeared when there was no wind, while an intense fire whirl could be created under wind. For the wind speeds of $0.24 \mathrm{~m} / \mathrm{s}$ and $0.49 \mathrm{~m} / \mathrm{s}$, a stable fire whirl lasted for a long time, which stood still or moved toward the leeward end before its disappearance. As shown in Fig. 2, an initial flame with weak swirl and downwind tilt underwent a transition to become stronglyrotating and erect, and then moved downwind over the line burner. The fire whirl flame height in this case reached about $2.5 \mathrm{~m}$. For increasing wind speed within a certain range, due to the significantly enhanced 
flame tilt, the weakly-swirling fire whirl quickly moved downwind and just when it reached the leeward end the intensity of swirling would have a sudden increase. When the wind speed was increased to some extent, no fire whirl would appear. The same situations also occurred for the $200 \mathrm{~cm}$ long burner. Tests results showed that it is impossible to create a fire whirl when the burner is far away from the ground surface or when the attack angle is $90^{\circ}$ or $0^{\circ}$. It is of great interest to notice that all the observed fire whirls rotated clockwise. Occasionally, more than two fire whirls were observed at the same time, but with considerably limited durations. Figure 3 shows one single fire whirl resulted from the merging of two fire whirls within less than one second.

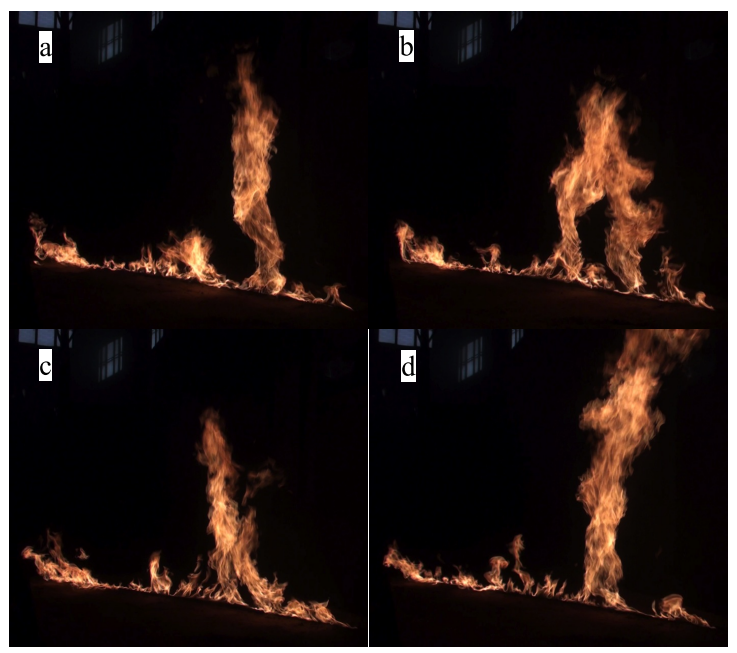

Fig. 3. Photos of the formation and combination of two fire whirls obtained from VD 2, at relative time moments of (a) $0 \mathrm{~s}$, (b) $0.4 \mathrm{~s}$, (c) $0.6 \mathrm{~s}$ and (d) $1.2 \mathrm{~s}$. The burner was $300 \mathrm{~cm} \times 5 \mathrm{~cm} \times 5 \mathrm{~cm}$ in size, with its rim flush with the ground surface. Wind speed: $0.49 \mathrm{~m} / \mathrm{s}$; attack angle: $25^{\circ}$.

\section{CONDITIONS AND MECHANISM OF THE FIRE WHIRL FORMATION}

Byram and Martin [8] suggested three essential conditions for fire whirl formation, i.e. a generating eddy, a fluid sink located within the eddy and some friction or drag offered to the movement of air in the ground of the eddy. The flame itself serves as a fluid sink that horizontally entrains the surrounding air to replace the upward hot gas. When there is an eddy in the surrounding air, the entrainment could induce the concentrated vortex for fire whirl formation. The friction appears to be connected with the stability or disappearance of fire whirl, because it serves to supply the air for the combustion of a steady fire whirl, as evidenced by Zhou et al [9].

\section{Eddy Source: the Effect of Ground Surface}

The viscous force is small in comparison with the inertial force for the flow of a steady fire whirl. However, it may play an important role in the initiation of fire whirl [3], which could be physically interpreted by the basic vorticity equation as follows.

$$
\frac{\partial \vec{\omega}}{\partial \mathrm{t}}+(\vec{V} \cdot \nabla) \vec{\omega}=(\vec{\omega} \cdot \nabla) \vec{V}-\vec{\omega}(\nabla \cdot \vec{V})+\nabla \times \vec{f}-\nabla\left(\frac{1}{\rho}\right) \times \nabla p+v \nabla^{2} \vec{\omega}
$$

where the last three terms in the right side represent the generation of vorticity due to the effect of nonconservative force, baroclinic fluid and viscous shear, respectively. A typical case of the vorticity generated by the viscous shear is the horizontal vorticity near the ground surface as wind blows over the ground surface. The second term in the left side stands for the advection of vorticity by wind, which suggests that the horizontal vorticity generated in the windward could affect the combustion behavior in the leeward. The first term in the right side shows that velocity gradient can bend and stretch the vortex line in the flow field. Thus, the horizontal vortex line can be transformed to a vertical one as it meets upward buoyant plume, and its strength can be enhanced due to the stretching effect of the upward buoyant plume. 
The above analysis can be validated by the experimental observations in Fig. 4, in which it is shown that fire whirls were created when the burner rim was flush with the ground surface or was $5 \mathrm{~cm}$ above the ground surface, while no fire whirl appeared for the burner rim being $53 \mathrm{~cm}$ above the ground surface. This implies that the concentrated vortex for the formation of fire whirl comes from the horizontal vorticity near the ground surface in the windward.

Figure 4 also suggests that the strength and duration of fire whirl would decrease as the vertical distance of the flame above the ground level increases, and thus there is a critical vertical distance over which no fire whirl would appear. This can also be theoretically interpreted by the vertical profile of vorticity as wind blows over the ground surface. As shown in Fig. 4(d), the vorticity decreases to be nearly zero as the vertical distance increases to be above the boundary layer. The critical vertical distance might be related to the boundary layer thickness.

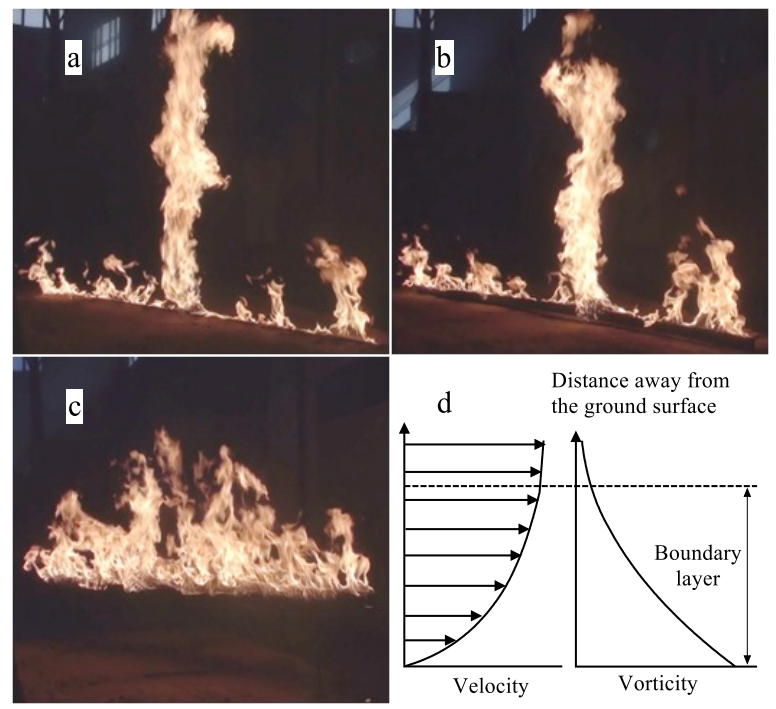

Fig. 4 Comparison of fire behaviors for the burner rim being respectively (a) flush with the ground surface, (b) $5 \mathrm{~cm}$ over the ground surface, and (c) $53 \mathrm{~cm}$ over the ground surface. The burner was $300 \mathrm{~cm} \times 5 \mathrm{~cm} \times$ $5 \mathrm{~cm}$ in size, with $0.49 \mathrm{~m} / \mathrm{s}$ wind speed and $25^{\circ}$ attack angle. (d) shows the vertical profile of velocity and vorticity.
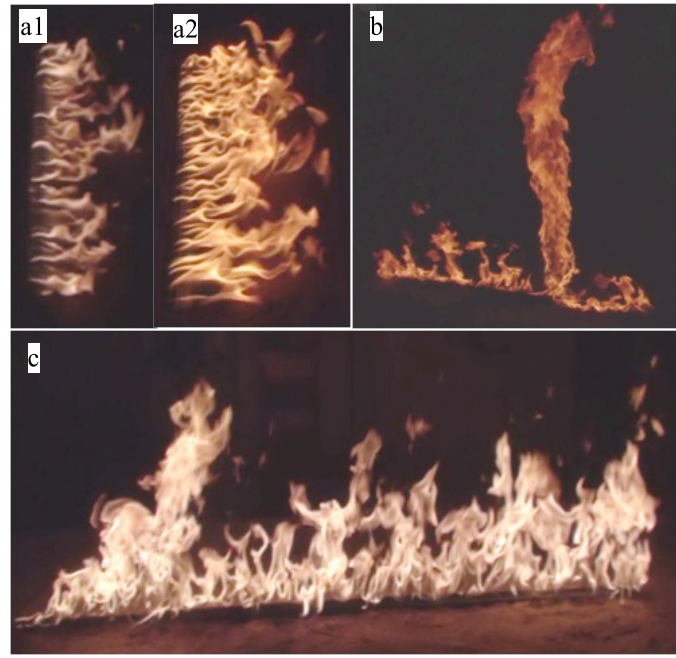

Fig. 5. Comparison of fire behaviors for different attack angles, including $90^{\circ}$ angle for the burners of (a1) $100 \mathrm{~cm} \times 3 \mathrm{~cm} \times 3 \mathrm{~cm}$ and (a2) $120 \mathrm{~cm} \times 6 \mathrm{~cm} \times 6 \mathrm{~cm}$, and (b) $30^{\circ}$ angle and (c) $0^{\circ}$ angle for the burner of $200 \mathrm{~cm} \times 5 \mathrm{~cm} \times 5 \mathrm{~cm}$. Wind speed was $0.49 \mathrm{~m} / \mathrm{s}$ and all burner rims were flush with the ground surface. 


\section{Coupling of Vortex and Fire Plume: the Effect of Attack Angle}

Fire whirl results from the interaction of concentrated vortex and upward fire plume. However, the horizontal vortex line near the ground surface cannot always be entrained into the fire plume to induce the concentrated vortex, even though the line burner rim is flush with the ground surface. As shown in Fig. 5, with $30^{\circ}$ attack angle a fire whirl formed, while both $0^{\circ}$ and $90^{\circ}$ never created fire whirls. This indicates that the attack angle plays another important role in the formation of fire whirl, and there may be a certain range of attack angle within which fire whirls may appear.

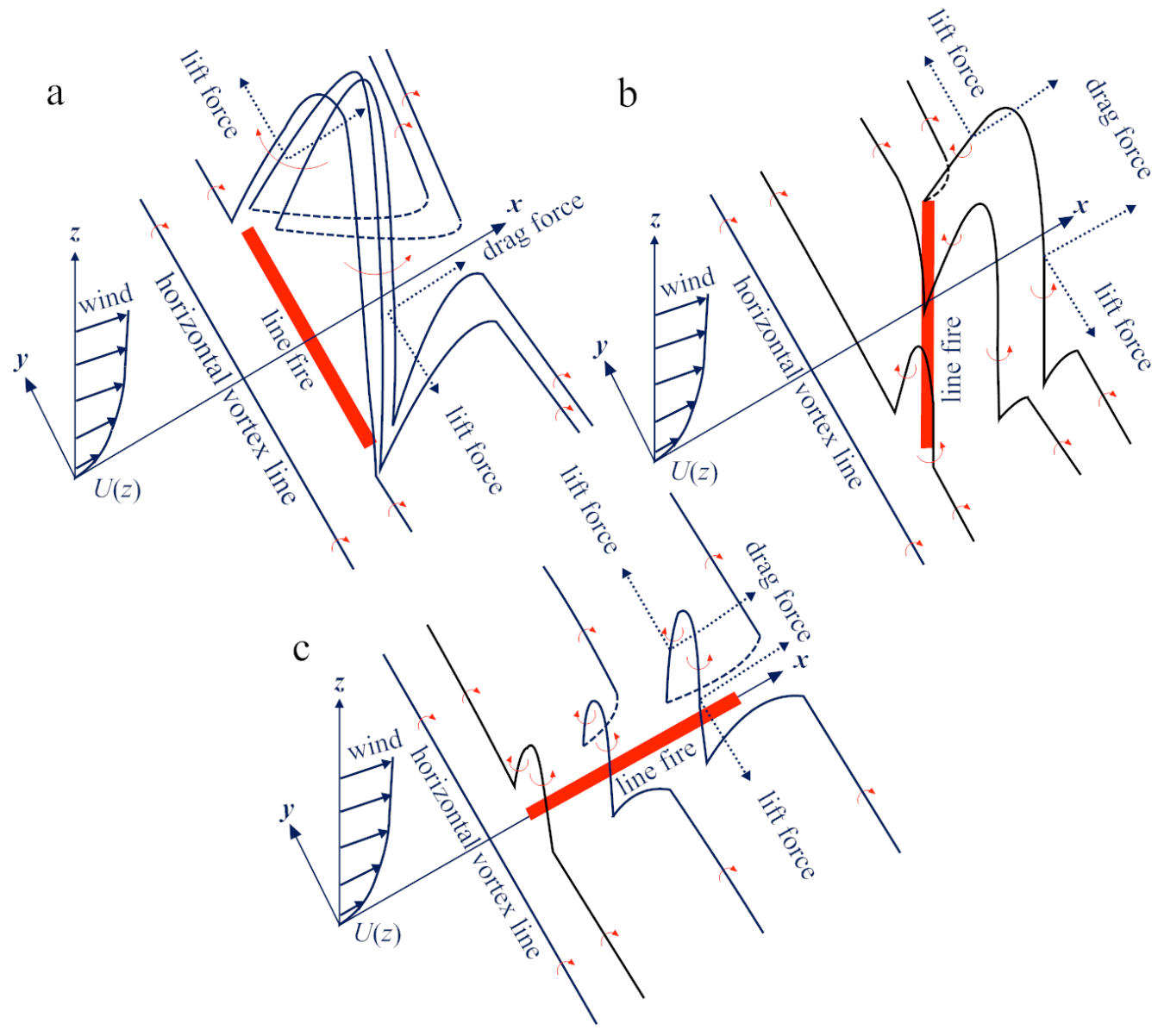

Fig. 6. Comparison of vortex line advections for three different attack angles.

In Fig. 6, the advection and bending of vortex lines are depicted to interpret the effect of attack angle on the formation of fire whirl. It is difficult for the vortex line to enter into the upward fire plume when the attack angle is $90^{\circ}$ and $0^{\circ}$, due to the lift force acting on the vortex line against the entrainment of the fire plume. For $0^{\circ}$ situation, even if the bended vortex line can be entrained into the fire plume from the long edges of burner, the vortex lines from the two directions will counteract due to the symmetry of entrainment. The weakly-rotating flame can be observed occasionally near the two short edges for the $0^{\circ}$ situation, but it is impossible to move towards the middle of the burner due to the lift force. However, the fire whirl may occur when the attack angle is between $0^{\circ}$ and $90^{\circ}$, if the resultant of drag and lift force is parallel to the long edge of the burner. The drag and lift force acting on the vortex line is defined in the following section. As observed during tests, fire whirls formed in the middle or leeward end of burner and always rotated clockwise. This observation can be qualitatively interpreted by the depiction in Fig. 6(b).

\section{Rotation Strength of Fire Whirl: the Effect of Wind Speed}

A reasonable wind speed is essential for the formation of fire whirl, which is validated by scale-model experiments (e.g. Emori and Saito [1], Soma and Saito [3], Kuwana et al [4, 6]). As stated above, with 
increasing wind speed the fire whirl produced by the line fire will first be weakly-rotating and then be strongly-rotating. The weak fire whirl could be induced due to the interaction among the jagged flames over the line burner in still air, while the strong one should result from the interaction between the cross wind and the upward plume. No fire whirl was observed for larger wind speed, which suggests that the wind speed should be within a certain critical range for the onset of fire whirl. This range could be related to the upward speed of buoyant plume. The characteristic upward speed can be expressed by $\sqrt{g H}$, where $g$ is the gravitational acceleration and $H$ is the flame length before formation of fire whirl [6]. Here, we formulate $H$ by the mean flame height of line fire in still air, as [10]

$$
H / w=3.64 \dot{Q}^{* 2 / 3}
$$

where $w$ is the burner width, and $\dot{Q}^{*}=\dot{Q} /\left(\rho_{\infty} c_{p, \infty} T_{\infty} g^{0.5} l w^{1.5}\right)$ is the dimensionless heat release rate, in which $\dot{Q}$ is the heat release rate, $l$ is the burner length, and $\rho_{\infty} c_{p, \infty}$ and $T_{\infty}$ are the density, specific heat and temperature of ambient air, respectively. In particular, Eq. (2) requires that the heat release rate per unit length $\dot{Q}_{l}=\dot{Q} / l$ should be over $30 \mathrm{~kW} / \mathrm{m}$. As listed in Table 1, the experimental characteristic upward speeds for $200 \mathrm{~cm}$ and $300 \mathrm{~cm}$ line fires were nearly the same, being $1.99 \mathrm{~m} / \mathrm{s}$ and $1.93 \mathrm{~m} / \mathrm{s}$, respectively. Thus, the critical range of wind speed for both line fires should be nearly the same, which can also be validated by the experimental results that both line fires created strong fire whirls when the wind speed was varied within $0.24-0.49 \mathrm{~m} / \mathrm{s}$. Therefore, the Froude number (dimensionless critical wind speed) $U_{c} / \sqrt{g H}$ should be within 0.12-0.25.

By use of Eq. (2), the Froude number can be rewritten as $U_{c} /\left((g w)^{0.5} \dot{Q}^{* 1 / 3}\right)$ that should be within 0.230.49. Kuwana et al [6] have also studied the critical wind speed for small-scale line fires to generate the fire whirls by experiment, suggesting the semi-empirical correlation $\log \left(U_{c} /(g L)^{1 / 2}\right)=\frac{1}{3} \log \left(\dot{Q}^{*}\right)-0.5$ where the characteristic length $L$ corresponds to the line burner width for a line fire and the dimensionless heat release rate ranges from $10^{-4}$ to 10 . That is to say, $U_{c} /\left((g L)^{0.5} \dot{Q}^{* 1 / 3}\right)$ approximately equals 0.32 . It is obvious that the Froude number $U_{c} / \sqrt{g H}$ being within $0.12-0.25$ is the critical range for a line fire to generate fire whirl.

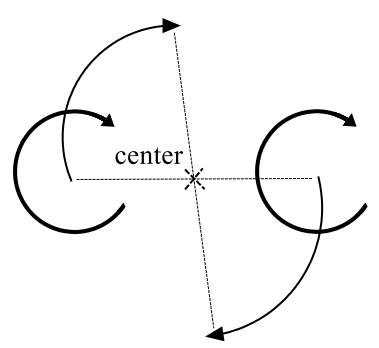

a

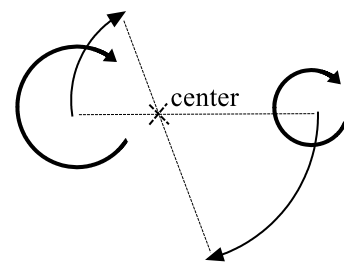

b

Fig. 7. Motion of two point vortices in the same rotational direction (a) for equal strengths and (b) for unequal strengths.

\section{Interaction between Two Fire Whirls}

In tests, occasionally more than two fire whirls were generated simultaneously over the line burner. Observation showed that the two fire whirls exerted influence to each other with some characteristic motions. For example, they generally involve the same rotation direction and may merge to become one single fire whirl (see Fig. 3). As we know, in fluid mechanics two point vortices may revolve around a center if they have the same direction of rotation. As depicted in Fig. 7, this center point is on the connecting line of the two point vortices, with zero velocity. In comparison with point vortex, fire whirl vortex holds a remarkable upward velocity that decreases with height, so the upper fire plume would 
involve obvious revolution (see Fig. 3b). However, it is impossible for the bottom flame to leave the burner in spite of the interaction. Two adjacent fires will lean toward each other, when with a small fire spacing between them, due to the limited space for air entrainment (see Fig. 3c). Therefore, two adjacent fire whirls would revolve around and lean toward each other, and finally they will merge to become one single fire whirl.

\section{MECHANISM OF FIRE WHIRL MOTION}

Before transition to be erect with a several-fold increase in height, the fire whirl flame is characterized by slight rotation and downwind inclination, and it will move toward the leeward end if the wind speed is large enough. The standing fire whirl shown in Fig. 2 was very stable with strong rotation. This section focuses on the mechanism of the evolution from the inclining flame and the movement over the line burner for such a standing fire whirl.

\section{Assumption of a Solid-Body Rotation}

The flow structure of fire whirl is significantly affected by rotation, and the velocity behaves like that in a normal solid-body rotation, characterized by the rotation inside the vortex core which is suppressed due to viscous dissipation, and the outside free vortex. Akhmetov et al [11] measured the tangential velocity of 12 cm-diameter alcohol fire whirl by PIV technology. Figure 8 shows the averaged tangential velocity over four directions successively separated by $90^{\circ}$ angles at the height of $10 \mathrm{~cm}$. The average treatment largely helped reduce the flame wander effect in the measurement. As shown, the Rankine vortex could be used to well formulate the radial profile of tangential velocity, which indicates an almost constant angular velocity inside the vortex core. Note that the vortex core radius (approximately $15 \mathrm{~cm}$ ) was much larger than the flame radius (below $6 \mathrm{~cm}$ ). Accordingly, the fire whirl flame body rotated like a solid-body. Moreover, the angular velocity of fire whirl inside the vortex core decreased with increasing vertical distance, however, the angular momentum outside the vortex core kept constant independent on the vertical distance [8]. The fire whirl flame is weakly-swirling with large radial inflow velocity near the ground surface where a strong friction exists. Thus, the fire whirl examined in this work can be simplified to be a spinning cylinder in a cross stream, but with a friction on its bottom.

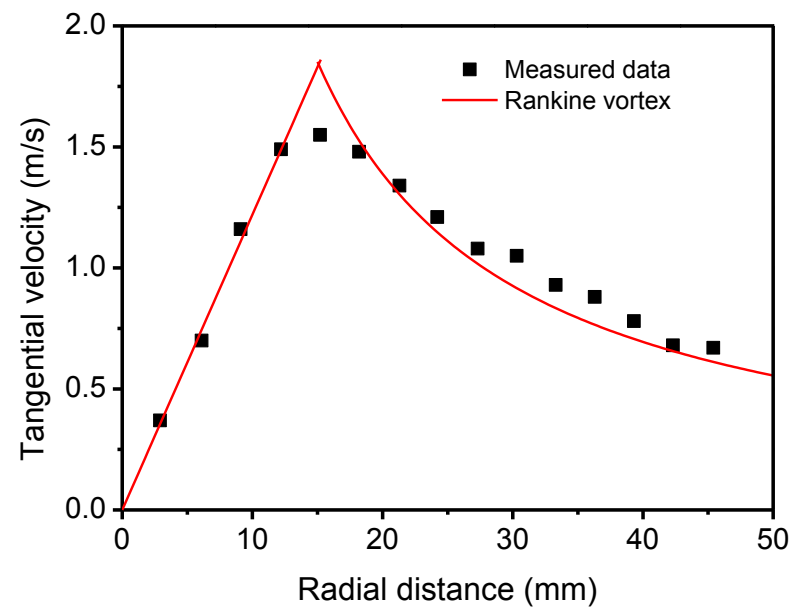

Fig. 8. Radial profile of tangential velocity (the experimental data is extracted from [11]).

\section{Force Analysis}

\section{Force Analysis of a Spinning Cylinder in a Cross Stream}

The movement of a spinning cylinder is dominated by the drag force and the lift force (known as Magnus effect) in a cross stream. The direction of the drag force is parallel to the stream direction while the lift force is perpendicular to the stream. The drag and lift forces are induced by the pressure and friction forces, 
for which the pressure difference dominates the lift force while the drag force is controlled by both the friction and the pressure [12]. The drag and lift forces can be respectively expressed as

$$
\begin{aligned}
& D=\frac{1}{2} C_{D} \rho U^{2} d \\
& L=\frac{1}{2} C_{L} \rho U^{2} d
\end{aligned}
$$

where $\rho$ is the fluid density, $U$ the steam flow speed, $d$ the cylinder diameter, $C_{D}$ and $C_{L}$ are the drag and lift coefficients determined by the flow field around the cylinder, respectively. Actually, the drag and lift forces involve fluctuations due to the vortex shedding behind the cylinder. Thus the coefficients can be respectively expressed by

$$
\begin{aligned}
& C_{D}=\bar{C}_{D}+C_{D}^{\prime} \\
& C_{L}=\bar{C}_{L}+C_{L}^{\prime}
\end{aligned}
$$

where the horizontal bar on the letters denotes the mean values, while the single apostrophe represents the fluctuation values. Generally, the flow field around a spinning cylinder is dominated by the Reynolds number ( $\operatorname{Re}=U d / v$ where $v$ is the kinematic viscosity) and the dimensionless rotary velocity ( $\alpha=\Omega d / U$ where $\Omega$ is the angular velocity). Therefore, the drag and lift coefficients also depend on the Re number and the dimensionless rotary velocity.

There have been many studies on the vortex shedding, as well as the drag and lift forces, of a spinning cylinder in a cross stream. Kumar et al [13] studied the vortex shedding at $\mathrm{Re}=200,300$ and 400 with the dimensionless rotary velocity varying from 0 to 5 by experiment, and observed that the vortex shedding activity only occurs at $0 \leq \alpha<\alpha_{\mathrm{I}}$ or $\alpha_{\mathrm{II}}<\alpha<\alpha_{\mathrm{III}}$, where $\alpha_{\mathrm{I}} \approx 1.95, \alpha_{\mathrm{II}} \approx 4.34$ and $\alpha_{\mathrm{III}} \approx 4.70$. Kang and Choi [12] conducted numerical simulation with $\mathrm{Re}=60,100$, and 160 in the range of $0 \leq \alpha \leq 2.5$, and indicted that $\bar{C}_{L}$ increases linearly and $\bar{C}_{D}$ decreases with increasing $\alpha$, and that $C_{L}^{\prime}$ stays nearly constant while $C_{D}^{\prime}$ increases with increasing $\alpha$ to be $\alpha_{\mathrm{I}}$ (being $1.4,1.8$ and 1.9 for $\mathrm{Re}=60$, 100, and 160, respectively). Stojkovic et al [14] presented the profile of $C_{D}$ as a function of $\alpha$ ranging from 0 to 6 with Re being from 60 to 200 . The $\bar{C}_{D}$ decreases to zero with increasing $\alpha$ to $\alpha_{\mathrm{II}}(\approx 4.2)$, and then fluctuates near zero as $\alpha$ increases to $\alpha_{\text {III }}(\approx 5.4)$, and is finally enhanced with a continuative increase in $\alpha$. The $C_{D}^{\prime}$ in the range of $\alpha_{\mathrm{II}}<\alpha<\alpha_{\mathrm{III}}$ is four times of that of $0<\alpha<\alpha_{\mathrm{I}}$, and stays at zero in other ranges. It should be noted that the three critical dimensionless velocities depend on the Re number.

In summary, the mean lift coefficient increases with the increase in dimensionless rotary velocity $\alpha$, while the mean drag coefficient is not a monotonic function of $\alpha$. The fluctuation drag and lift coefficients are zero in the specific range of $\alpha$ where the vortex shedding is completely suppressed.

\section{Force Analysis of Fire Whirl Flame}

Wake vortex shedding can be observed in the backside of a cylinder in a cross stream, as well as that of a jet fire or a pool fire in a cross wind $[15,16]$. Thus, the drag and lift forces on the fire whirl flame could also involve fluctuations. Figure 9 shows the forces acting on the fire whirl flame which rotates clockwise. Besides the drag and lift forces, the friction force exists between the weakly-swirling flame root and ground surface, to balance the drag and lift forces and make the fire whirl flame to stand stably.

The movement of fire whirl can be predicted when the drag and lift forces are known. When the weaklyswirling fire whirl appears with a downwind inclination, the lift force begins to increase and the drag force starts to decrease to some extent. When the resultant of drag and lift force in the $y$-axis direction becomes zero, the inclined fire whirl will stand up with an increasing rotation which can significantly entrain the fresh air from ambient as well as fuel vapor. The fire whirl flame height will be largely enhanced while the burning near the fire whirl will be significantly suppressed, as shown in Fig. 2. At the same time, the actual 
contact areas between the flame of the fire whirl and the fuel surface will increase, and in turn the friction force will increase. According to the above analysis, the standing fire whirl is possibly able to hold the dimensionless rotary speed between $\alpha_{\mathrm{I}}$ and $\alpha_{\mathrm{II}}$, and so it can move without fluctuation over the line burner. If the resultant of drag and lift forces can overcome the friction force, the fire whirl moves toward the leeward end. Otherwise, the fire whirl stands still. If the dimensionless rotary speed of fire whirl is less than $\alpha_{\mathrm{I}}$, the fire whirl may move backward and forward over the line burner because the large fluctuant amplitude may make the resultant of drag and lift forces being negative. Due to some uncertain factors, such as the disturbance of wind speed or the surrounding air, the generated fire whirl cannot last until the fuel is completely burned. Therefore, accurate measurements should be conducted to quantitatively determine the three forces in the future work.

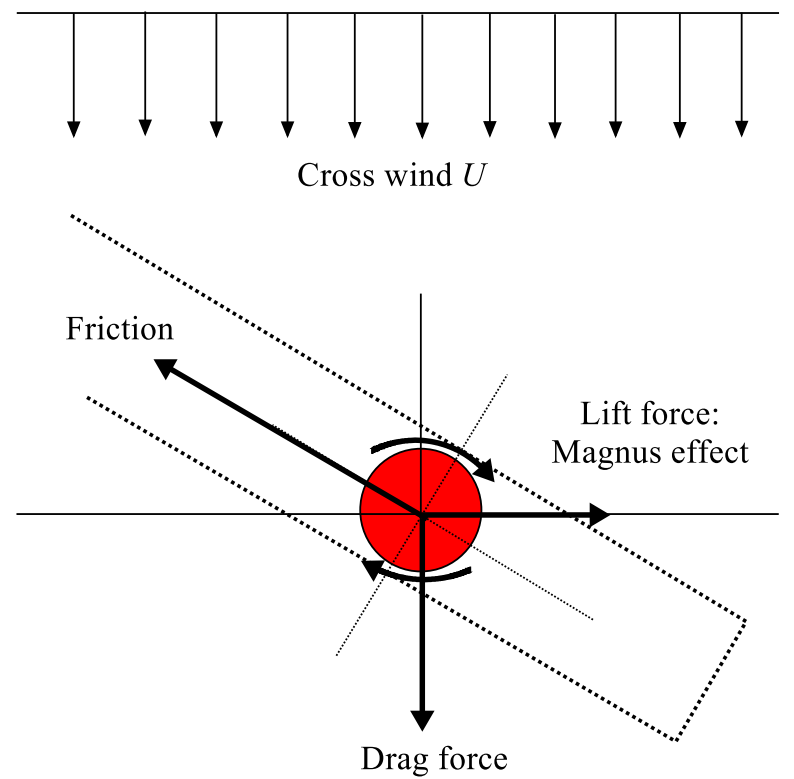

Fig. 9 Forces acting on the moving fire whirl flame.

\section{CONCLUSIONS}

This paper presents an elementary study on the fire whirl due to the interaction between line fire and cross wind by experiments. The major conclusions are summarized as follows.

(1) The formation conditions for the fire whirl in a line fire include the line fire near the ground, a reasonable attack angle between the line fire and the cross wind, and wind speed within a critical range.

(2) In a line fire, the concentrated vortex of fire whirl results from the coupling of the line fire plume and the horizontal vortex line near the ground surface.

(3) The disbalance among the drag force, lift force and ground friction can be implied to be the dominant mechanism which controls the flame moving behavior in the fire whirl of line fire.

Table 1 Characteristic upward speed of line fire plume

\begin{tabular}{ccccccccc}
\hline $\boldsymbol{l}(\mathbf{c m})$ & $\boldsymbol{w}(\mathbf{c m})$ & mass (g) & time (s) & $\dot{\boldsymbol{Q}}^{(\mathbf{k W})}$ & $\dot{\boldsymbol{Q}}_{l}(\mathbf{k W / m})$ & $\dot{\boldsymbol{Q}}^{*}$ & $\boldsymbol{H}(\mathbf{c m})$ & $\sqrt{\boldsymbol{g H}}(\mathbf{m} / \mathbf{s})$ \\
\hline 200 & 5 & 1376 & 760 & 81 & 40 & 0.104 & 40 & 1.99 \\
300 & 5 & 1376 & 544 & 112 & 37 & 0.096 & 38 & 1.93 \\
\hline
\end{tabular}

${ }^{\mathrm{a}}$ The heat release rates were calculated by assuming unity of combustion efficiency with the complete combustion heat for heptane, i.e. $44.6 \mathrm{~kJ} / \mathrm{g}$.

${ }^{\mathrm{b}}$ The temperature, density and specific heat of ambient air are $298 \mathrm{~K}, 1.1707 \mathrm{~kg} / \mathrm{m}^{3}$ and 1.007

$\mathrm{kJ} /(\mathrm{kg} \cdot \mathrm{K})$, respectively. 


\section{ACKNOWLEDGEMENT}

This work was sponsored by the National Basic Research Program of China (973 Program, No. 2012CB719702), the National Key Technology R\&D Program under Grant 2011BAK07B01-02, and National Natural Science Foundation of China under Grant 51120165001 and 51076148. This work was also financially supported by Jiangsu Science-technology Support Plan Projects (No.BE2012671). Naian Liu was supported by the Fundamental Research Funds for the Central Universities (No. WK2320000020).

Correspondence to this paper should be addressed to Prof. Naian LIU, liunai@ustc.edu.cn.

\section{REFERENCES}

[1] Emori, R., and Saito, K., (1982) Model experiment of hazardous forest fire whirl, Fire Technology 18: 319-327, http://dx.doi.org/10.1007/BF02473115.

[2] Dessens, J., (1962) Man-made Tornadoes, Nature 193: 14-15, http://dx.doi.org/10.1038/193013a0.

[3] Soma, S., and Saito, K., (1991) Reconstruction of fire whirls using scale models, Combustion and Flame 86: 269-284, http://dx.doi.org/10.1016/0010-2180(91)90107-M.

[4] Kuwana, K., Sekimoto, K., Saito, K., and Williams, F. A., (2008) Scaling fire whirls, Fire Safety Journal 43: 252-257, http://dx.doi.org/10.1016/j.firesaf.2007.10.006.

[5] Liu, N., Liu, Q., Deng, Z., Kohyu, S., and Zhu, J., (2007) Burn-out time data analysis on interaction effects among multiple fires in fire arrays, Proceedings of the Combustion Institute 31: 2589-2597, http://dx.doi.org/10.1016/j.proci.2006.08.110.

[6] Kuwana, K., Sekimoto, K., Minami, T., Tashiro, T., and Saito, K.., (2013) Scale-model experiments of moving fire whirl over a line fire, Proceedings of the Combustion Institute 34: 2625-2631, http://dx.doi.org/10.1016/j.proci.2012.06.092.

[7] Jiang, P., and Lu, S., "Effects of cross air flow on mass loss rates of circular aviation fuel pool fires in large open space," Ninth Asia-Oceania Symposium on Fire Science and Technology, International Association for Fire Safety Scienc, 2012, in press.

[8] Byram, G., and Martin, R., (1970) The modeling of fire whirlwinds, Forest Science 16: 386-399.

[9] Zhou, K., Liu, N., Lozano, J. S., Shan, Y., Yao, B., and Satoh, K., (2013) Effect of flow circulation on combustion dynamics of fire whirl, Proceedings of the Combustion Institute 34: 2617-2624, http://dx.doi.org/10.1016/j.proci.2012.06.053.

[10] Yuan, L. M., and Cox, G., (1996) An experimental study of some line fires, Fire Safety Journal 27: 123-139, http://dx.doi.org/10.1016/S0379-7112(96)00047-1.

[11] Akhmetov, D., Gavrilov, N., and Nikulin, V., (2007) Flow structure in a fire tornado-like vortex, Doklady Physics 52: 592-595, http://dx.doi.org/10.1134/S1028335807110055.

[12] Kang, S., Choi, H., and Lee, S., (1999) Laminar flow past a rotating circular cylinder, Physics of Fluids 11: 3312-3321, http://dx.doi.org/10.1063/1.870190.

[13] Kumar, S., Cantu, C., and Gonzalez, B., (2011) Flow Past a Rotating Cylinder at Low and High Rotation Rates, Journal of Fluids Engineering 133: 0412011-0412019, http://dx.doi.org/10.1115/1.4003984.

[14] Stojkovic, D., Schon, P., Breuer, M., and Durst, F., (2003) On the new vortex shedding mode past a rotating circular cylinder, Physics of Fluids 15: 1257-1260, http://dx.doi.org/10.1063/1.1562940.

[15] Fric, T. F., and Roshko, A., (1994) Vortical Structure in the Wake of a Transverse Jet, Journal of Fluid Mechanics 279: 1-47, http://dx.doi.org/10.1017/S0022112094003800.

[16] Shinohara, M., and Matsushima, S., (2012) Formation of fire whirls: Experimental verification that a counter-rotating vortex pair is a possible origin of fire whirls, Fire Safety Journal 54: 144153, http://dx.doi.org/10.1016/j.firesaf.2012.03.009. 